This is the final peer-reviewed accepted manuscript of:

G. Valenti, A. Fiorani, H. Li, N. Sojic, F. Paolucci.

Essential Role of Electrode Materials in Electrochemiluminescence Applications.

ChemElectroChem 2016, 3, 1990 - 1997

The final published version is available online at:

https://chemistry-europe.onlinelibrary.wiley.com/doi/10.1002/celc.201600602

Rights / License:

The terms and conditions for the reuse of this version of the manuscript are specified in the publishing policy. For all terms of use and more information see the publisher's website. 


\title{
Essential role of electrode materials in electrochemiluminescence applications
}

\author{
Giovanni Valenti, ${ }^{[a]}$ Andrea Fiorani, ${ }^{[a]}$ Haidong Li,${ }^{[b]}$ Neso Sojic ${ }^{[b]}$ and Francesco Paolucci ${ }^{[a] *}$ \\ Dedication This paper is part of the ChemElectroChem Focus Issue Honoring Christian Amatore
}

\begin{abstract}
The phenomenon of electrochemiluminescence $(E C L)$ is luminescence triggered by electrochemical reactions at electrodes. Heterogeneous electron transfers are deeply dependent on electrode materials, therefore, besides the usual parameters, the right choice of the electrode is a crucial point to address properly in order to maximize the emission efficiency. Many different electrodes have been studied, from metallic -platinum or gold- through transparent indium-doped tin oxide to carbon based electrodes, and others, such as paper based and boron doped diamond. This review summarizes results of $E C L$ at different electrode surfaces, disclosing the relative advantages and disadvantages, with a particular attention to the reference $\mathrm{Ru}(\mathrm{bpy})_{3}{ }^{2+} / \mathrm{TPrA}$ coreactant system. In other words, we offer an insight to recognize and select the optimal electrode material for the ECL systems of interest with particular emphasis on the biosensing applications
\end{abstract}

\section{Introduction}

Electrochemically-generated chemiluminescence or simply electrochemiluminescence $(E C L)$ is a luminescent phenomenon induced by electrochemical stimulus in which species generated at electrodes undergo high-energy electron transfer reaction to form light-emitting excited states..$^{[1,2]}$ Traditionally, ECL was generated via annihilation, which involved homogeneous electron-transfer reactions between electrochemically generated anion and cation, both produced for example at an electrode by alternate pulsing of the potential or at microelectrode arrays. ${ }^{[3]}$ This approach is typically called "annihilation", and the general mechanism is schematized below:

$\begin{array}{lll}\mathrm{P} & \rightarrow & \mathrm{A}+\mathrm{e} \\ \mathrm{P}+\mathrm{e} & \rightarrow & \mathrm{D} \\ \mathrm{A}+\mathrm{D} & \rightarrow & \mathrm{P}^{*}+\mathrm{P} \\ \mathrm{P}^{*} & \rightarrow \quad \mathrm{P}+h v\end{array}$

Scheme 1. Reaction pathway of $E C L$ annihilation route: $P=$ luminophore, $A=$ oxidized luminophore, $D=$ reduced luminophore and $\mathrm{P}^{*}=$ luminophore excited state.

This reaction pathway involves high reactive intermediates and generally requires pure aprotic solvents with large potential windows where the solvent reduction or oxidation does not affect the stability of $A$ and $D$.

In the 80 's Bard ${ }^{[4]}$ and co-workers presented for the first time a new approach for generating ECL, the so-called coreactant approach. It was a crucial point for the implementation of this transduction in the analytical fields. In fact this strategy opened the application of ECL to the water environments, as all the bio-related samples or analytes requires. Unlike the typical annihilation procedure, in this kind of $\mathrm{ECL}$, the excited state is generated through the reaction between two different precursors, an emitter (i.e. the luminophore) and a coreactant. The coreactant can be chosen among different classes of chemicals, and its fundamental feature is to present a highly unstable oxidised (or reduced) form that undergoes a fast chemical degradation, thus forming a high-energy radical. Two different mechanisms are then possible, depending on the nature of the coreactant, i.e., the "oxidative-reduction" or the "reductive-oxidation" one. ${ }^{[5]}$

As an analytical technique, the coreactant-based ECL represents an ideal marriage between electrochemical and spectroscopic methods combining good spatial resolution with high sensitivity. ${ }^{[6,7]}$ In the last 20 years the research activity on ECL exponentially increases, reaching more than 1000 publications per year in $2013,{ }^{[8]}$ in particular thanks to the clinical and bio-analytical applications. In fact the electrochemical way to initiate the emission, i.e. the output analytical signal, allows to obtain sensors where the transduction time and position is controlled, with very low background and high sensitivity even in a complex matrix, such as urine, blood or lysate. ${ }^{[9]}$ 
Although in the last few years many ECL systems were proposed, the oxidative-reduction strategy based on the tris(2,2'-bipyridine) ruthenium (II) $\left[\mathrm{Ru}(\mathrm{bpy}) 3^{2+}\right]$ as emitter and tripropylamine (TPrA) as sacrificial coreactant is the only one that have a real commercial application. In this case the general mechanism involves the oxidation of both emitter and coreactant as schematize in figure 1a.

The first ECL commercial instrumentation was produced in the 1994 by IGEN International. Nowadays, a development of this instrument by Roche, called Elecsys, is based on the combination between magnetic microbeads technology, fluidic system and ECL output signal. It results in the most used ECL instrumentation for the clinical analysis. ${ }^{[10]}$ Another important ECL analyser which is focused on the multiplexing analysis, is commercialized by Meso Scale Discovery. ${ }^{[11]}$ Recently, Dropsens start the commercialization of promising analytical tools based on ECL for the screen-printed electrode application. ${ }^{[12]}$

All these systems based on $\mathrm{Ru}(\mathrm{bpy}) 3^{2+} / \mathrm{TPrA}$ couple need the oxidation of both chemical species, while in the common immunoassay the $\mathrm{Ru}(\mathrm{bpy})_{3}{ }^{2+}$ is not directly oxidized because it is used as an ECL label attached to the bead and therefore not free to diffuse toward the electrode. Bard and co-workers ${ }^{[13]}$ demonstrated how ECL emission could be obtained only from the oxidation of TPrA, in a mechanism involving both $\operatorname{TPrA} A^{\bullet}$ and $\operatorname{TPrA}{ }^{\bullet+}$ (Figure 1b). Given the complexity of the coreactant mechanism involved in the generation of excited state, numerical digital simulation has proven to be a powerful tool to investigate and optimize the ECL process. ${ }^{[14]}$ Amatore and co-workers deciphered the complex mechanistic processes using digital simulation to investigate the kinetic and thermodynamic parameters associated with the ECL generation. ${ }^{[15]}$ They also examined the effect of diffusion coefficient, of both coreactant and ECL active luminophore, on the ECL mechanism. ${ }^{[15 a]}$ Herein, they observed that the relative contribution of the ECL mechanisms changes (from Figure 1a to $1 \mathrm{~b}$ ) by decreasing the diffusion coefficient of the luminophore.

A crucial point in the efficiency of the ECL generation is the chemical and physical state and behaviour of the electrode surface where the ECL process is initiated. In fact, one of the key steps for the optimization of the signal to noise ratio is the coreactant heterogeneous electron-transfer reaction. In particular, TPrA-based ECL is driven by this reaction and thus strictly depends on the kinetics of the heterogeneous electron-transfer that largely differs for different electrode materials. It is well known that the electrode surface may change its interfacial behaviour during the potential ramp used in the ECL generation and this might dramatically affect the efficiency of the emission intensity. In fact the electrode surface propriety might also affect the lifetime of TPrA ${ }^{\cdot+}$ and its deprotonation reaction kinetics, thus generating free radicals, TPrA', closer to the electrode surface and increasing the contribution of the oxidative consumption (as shown by the dashed line in Figure 1b). Moreover, surface modification by intermediates adsorption, such as radical cation or coreactant by-products, are known to poison the electrode surface. ${ }^{[16]}$ This effect might decrease the ECL intensity and modify the stability of the electrode after repeated emission cycles.

Here, we reported a practical guide on the ECL and the effects of the different electrode materials on the ECL generation with particular attention for the biosensing applications, focussing on the model $\operatorname{Ru}(\mathrm{bpy}) 3^{2+} / \operatorname{TPrA}$ coreactant system. 


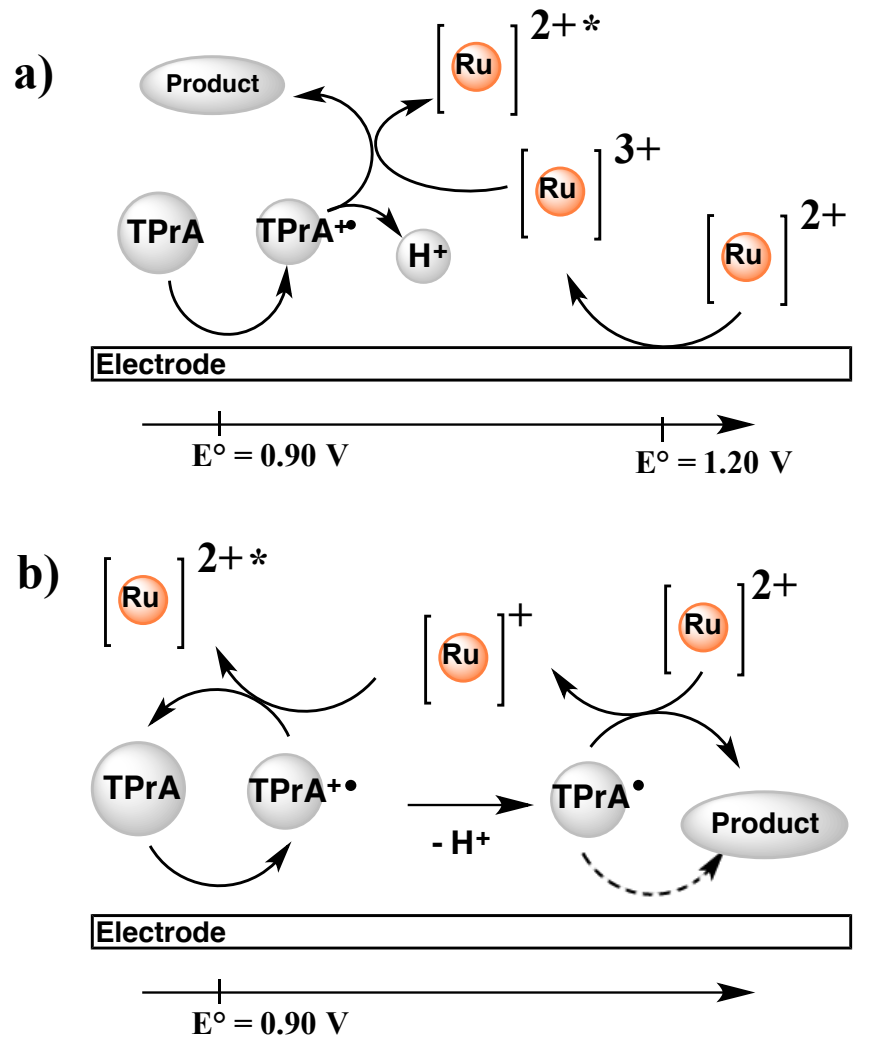

Figure 1. ECL mechanisms for the couple $\mathrm{Ru}(\mathrm{bpy}) 3_{3}{ }^{2+} / \mathrm{TPrA}$ : a) both, luminophore and coreactant, are oxidized in the "oxidative-reduction" mechanism; b) ECL generation obtained only by TPrA oxidation and involving the homogeneous reaction of the radical cation (TPrA ${ }^{\bullet}+$ ), as proposed by Bard.[13] The luminophore in the excited state $\mathrm{Ru}^{2+*}$ relaxes to the ground state and emits photon. Reproduced from ref. [14], copyright 2015, with permission of American Chemical Society.

\section{Noble electrode materials: platinum and gold}

Platinum and gold electrodes are widely used electrode materials in electrochemistry. In particular, in molecular electrochemistry thanks to the typical fast kinetics of electrons transfer reactions and electrochemical induced reactions. For this reason, platinum and gold are largely used for the ECL investigation of new luminophores in organic solvents. In fact, ECL emission generated by annihilation method typically required strictly aprotic solvent, such as acetonitrile or dichloromethane, and large working potential windows. ${ }^{[17]}$ In this context, those noble metals are the most employed electrode materials for annihilation ECL and are mainly exploited to characterize new ECL luminophores such as Iridium ${ }^{[18]}$ or Ruthenium ${ }^{[19]}$ coordination complexes, bodipy ${ }^{[20]}$ and polycyclic aromatic hydrocarbons. ${ }^{[21]}$

For practical applications, i.e. in water, platinum is not largely used because the high potential necessary to generate the ECL emission, typically in the range of 0.8-1.2 V, might involve electrode modification (Table 1). It is known that in neutral condition platinum might be oxidized generating an oxide layer that affects the efficiency of ECL emission ${ }^{[22]}$ (Figure 2a). In addition platinum is highly reactive towards the water oxidation and proton reduction generating bubbles at the electrode. As a matter of fact Pt electrode shows 100 times lower ECL compared with the glassy carbon electrode for the $\operatorname{TPrA} / \mathrm{Ru}(\mathrm{bpy}) 3^{2+}$ system in the biosensor operando condition. ${ }^{[23]}$ The strategy proposed to overcome these disadvantages was the coating of Pt electrode surface with surfactants, both ionic ${ }^{[24]}$ or non-ionic ${ }^{[25]}$. The overall effect is to protect the surface by decreasing the oxide formation; hence a higher amount of TPrA can be readily oxidized, leading to an enhanced ECL emission.

The other noble metal frequently used, gold, showed typically a wide range of electrochemical applications also in aqueous solutions. ${ }^{[23,26,27]}$ Similar to platinum, one of the main drawbacks is the surface oxide formation in aqueous media. ${ }^{[28,29]}$ However, the ECL intensity with gold electrode, for the Ru(bpy) ${ }^{2+} / \operatorname{TPrA}$, is $\sim 10$ times higher than that at Pt electrode in the same experimental conditions. ${ }^{[2,23]}$ This differences in the ECL efficiency reflects the different reactivity of the materials, i.e. the growth of surface gold oxide, that starts near $0.65 \mathrm{~V}$ (vs SCE), ${ }^{[30]}$ 
approximately $0.4 \mathrm{~V}$ more positive than platinum (Figure $2 \mathrm{~b}$ ). ${ }^{[22]}$ This difference in the $\mathrm{ECL}$ intensity can be attributed to the decrease of TPrA oxidation rate due to the passivation of the electrode surface by oxide generation in this potential region, rather than diffusion control. ${ }^{[22]}$ This behavior was also observed with different amines. ${ }^{[23]}$

In order to circumvent the oxide generation phenomenon, the main strategy developed is the modification of gold surface with surfactants or with alkanethiols. The latter case that involves self-assembled monolayers was proved to be very effective. Both these surface modifications inhibit the oxide growth and it makes the electrode surface more hydrophobic. ${ }^{[30,31]}$ A similar effect can be obtained adding a small amount of halide that competes with the surface oxides growth, lowering the passivation of the electrode surface, and activating the electrode surface by anodic dissolution of gold. ${ }^{[22]}$ Another possible drawback of noble metal electrodes concerns the poisoning of the surface due to the adsorption of coreactant side products. This might modify the stability of the electrode after repeated emission cycles. ${ }^{[16]}$
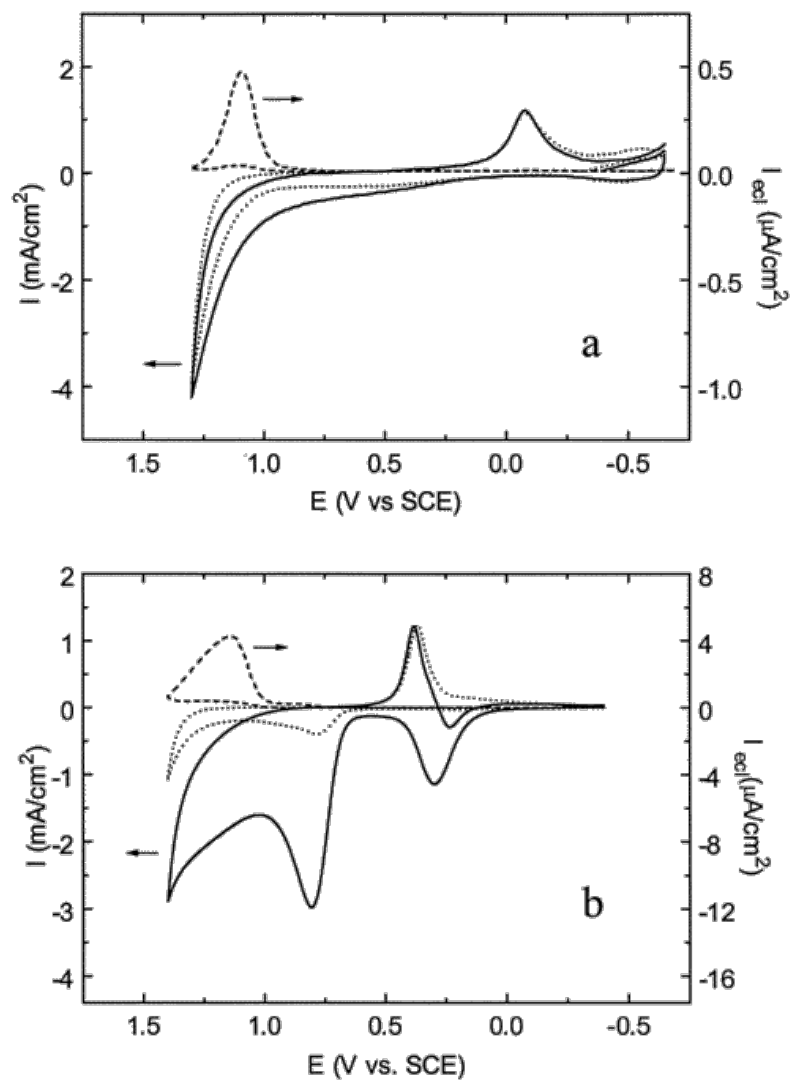

Figure 2. Cyclic voltammogram and $E C L$ curve at (a) platinum and (b) gold electrodes in $0.15 \mathrm{M}$ phosphate buffer solutions $(\mathrm{pH} 7.5)$ containing $100 \mathrm{mM}$ TPrA and $1 \mu \mathrm{M}$ Ru(bpy) $3^{2+}$. The dotted line represents data in the absence of both $\mathrm{Ru}(\mathrm{bpy})_{3}{ }^{2+}$ and TPrA. Potential scan rate, $0.1 \mathrm{~V} / \mathrm{s}$. Reproduced from ref. [22], copyright 2000, with permission of American Chemical Society.

Gold materials were applied for the ECL of luminol in neutral or basic aqueous solution, ${ }^{[32]}$ also in the form of gold nanorods/nanoparticles modified electrodes. ${ }^{[33]}$ In addition to flat electrode surfaces, porous gold electrodes ${ }^{[34]}$ were used to enhance the ECL signal compared to flat gold electrode of CdTe quantun $\operatorname{dots}^{[35]}$ or as scaffold for loading $\mathrm{Ru}(\mathrm{bpy}) 3^{2+}$ in a solid state ECL device. ${ }^{[36]}$

As a historical note, gold electrodes were used in the first commercial flow cell produced by lgen $^{[37]}$ for its $\mathrm{ECL}$ analyser Origen.

\section{Carbon-based materials}

Carbon-based materials and nanomaterials are widely exploited for ECL applications in biosensing, thanks to the fast kinetics for the amine oxidation. Glassy carbon electrodes (GCEs) are the most used electrode material to generate $\mathrm{ECL}$ in water with the standard $\mathrm{Ru}(\mathrm{bpy}) 3_{3}{ }^{2+} / \mathrm{TPrA}$. On one hand, this electrodic material combines fast electron transfer for the coreactant oxidation, in particular amine, and high overpotentials for the water oxidation that minimizes the generation of bubble 
at the potential required for the ECL emission (Table 1). On the other hand, GCEs might change the surface properties during the oxidation potential step. It has been reported that the oxidation of TPrA at the anodically pretreated GCEs became easier, while the ECL intensity could be greatly suppressed and this is attributed to the rapid deprotonation of $\operatorname{TPrA}^{\cdot+}$ cation radicals by the aid of oxygen-containing surface species formed on the GCE during the pretreatment. Because the reactivity of $\operatorname{TPr} A^{\cdot+}$ was increased, the radical intermediates product, $\operatorname{TPr} \mathrm{A}^{*}$ free radicals, would be more subject to oxidative consumption at the electrode subsequently (as shown by the dashed line in Figure 1b), leading to weaker ECL signals (Figure 3). When the ECL was produced mainly following a catalytic route, however, the electrode surface effect was much less significant. ${ }^{[38]}$ As a matter of fact, GCE shows 10 times and 100 times higher ECL intensity compared to gold and platinum, respectively. ${ }^{[22]}$ Furthermore, GCE are used also in organic solvents, such as acetonitrile, for the characterization of inorganic complexes such as Ru or $\mathrm{Ir},{ }^{[39]}$ and with tertiary amines as coreactant. ${ }^{[40]}$

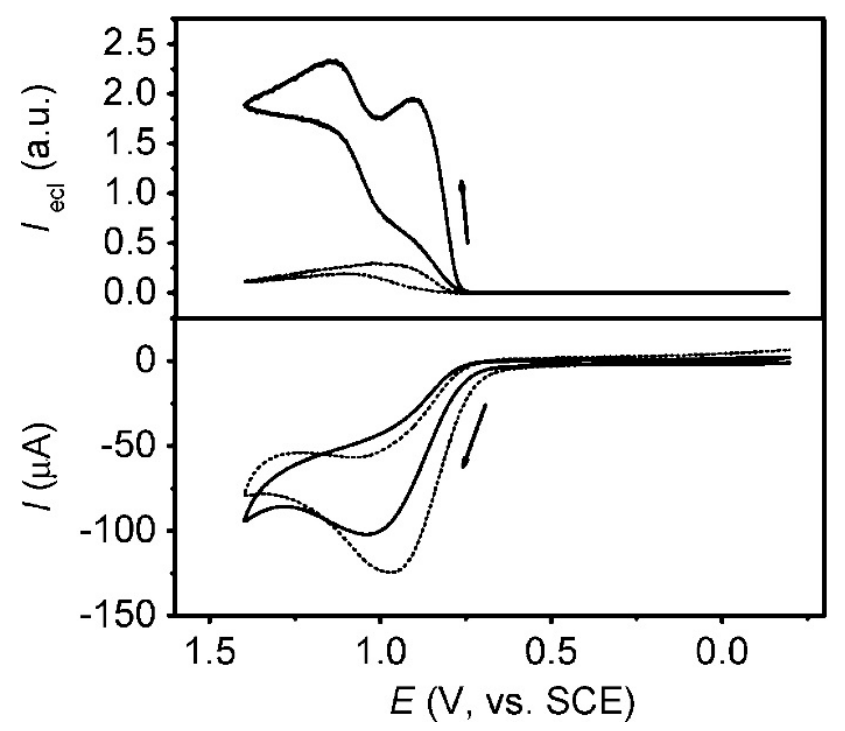

Figure 3. CV-ECL curves of $1 \mu \mathrm{M} \mathrm{Ru}(\mathrm{bpy})_{3}{ }^{2+}$ and $10 \mathrm{mM}$ TPrA in $0.15 \mathrm{M}$ PBS $(\mathrm{pH} 7.5)$ at a freshly polished GCE (solid line) and the GCE pretreated in the potential range of -0.2 to $+1.8 \mathrm{~V}$ for 10 cycles (dashed line). Scan rate $100 \mathrm{mV} / \mathrm{s}$. Reproduced from ref. [38], copyright 2008, with permission of American Chemical Society.

Modified GCE was recently reported as an efficient electrode material for the direct detection of medically relevant biomarker, such as dopamine, in whole blood without the need for sample pretreatment or extraction procedures to be undertaken. ${ }^{[41]}$ The main drawbacks of GCEs and carbon-based nanomaterial are the defects intrinsic to the carbon structures, such as $\mathrm{sp}^{3}$ carbon or edges. Indeed, the quality of the materials plays a crucial role. Defect in carbon-based materials might generate a strong unspecific signal, increasing the analytical background. Nowadays, carbon electrodes find commercial application in the Meso Scale analyser. ${ }^{[11]}$

Over the last decade, there has been a steady increase in the development of new electrodes that synergistically combine carbon nanostructured material with ECL. ${ }^{[6,42]}$ As one of novel carbon materials, ordered mesoporous carbons have attracted increasing attention in many fields including ECL and was recently used for the determination of dopamine. ${ }^{[43]}$ Another, carbon material very popular in the biosensor field are the carbon nanotubes. Rusling and Forster recently demonstrate the high superior sensitivity of CNTs forest for the prostate cancer detection with a limit of detection down to $1 \mathrm{pg} \mathrm{mL}^{-1}$ in patient serum. ${ }^{[44]}$ In addition they also reported the vertically aligned CNT forest array platforms using ink-jet printer to create versatile 'lab-on-a-chip' devices. This array emits ECL upon application of suitable positive voltage and the CCD placed above the array captures the emitted light from the spot simultaneously. In this context, in the recent years, graphene-based electrodes were largely used as new innovative material for ECL.[45] Graphene was also recently described, by Wang and coworkers, in a new concept of ECL immunoassay based on the ECL generation out of the Helmholtz plane (OHP) that led to about 1000 -fold improvement on sensitivity. ${ }^{[46]}$

\section{Transparent electrodes}

The transparency of electrodes is a property of fundamental importance, especially when combined with luminescence techniques, such as ECL and microscopy. Light collected through the electrode reduces error due to scattering processes of the solution and inner filter effects (reabsorption and self-absorption), that usually result in shifts up to $10-20 \mathrm{~nm}$ in peak wavelength. Transparent electrodes for ECL application might be divided in two 
main categories: glass/metal oxide and carbon based electrodes. Beside different degrees of transparency, they have typical electrochemical and surface properties that influence the heterogeneous electron transfer kinetic. ${ }^{47,}$ 48]

Transparent metal oxide electrodes, ${ }^{[49]}$ such as indium-doped tin oxide (ITO) and fluorine-doped tin oxide (FTO), are currently the standard materials for transparent electrodes. The stability of oxides limits the potential window, where anodic polarization favor dissolution, while at negative polarization indium or/and tin metals appear on the electrode surface ${ }^{[50]}$ Although the ITO offers the advantage of surface functionalization, ${ }^{[51]}$ the poor electrochemical behavior of $\mathrm{Ru}(\mathrm{bpy}) 3^{2+}$ displays a peak separation of $105 \mathrm{mV}$, while on gold it is $58 \mathrm{mV}$. This is an expected separation for semiconductor electrodes, such as ITO. Despite this, ITO electrodes were efficiently used for the system Ru(bpy) ${ }_{3}{ }^{2+} / \mathrm{TPrA}^{\left[{ }^{[2]}\right.}$ Furthermore, when used for luminol ECL, the low efficiency of oxidation compared with other materials favors the formation of chemiluminescent products rather than more oxidized products that do not generate light. ${ }^{[52]}$

Amatore and co-workers combined, for the first time, spatial visualization with ECL in order to observe, with high resolution, concentration profiles of species generated at the

microelectrodes or electrode array. ${ }^{[3]}$ Recently, transparent electrodes paved the way for new imaging techniques based on ECL, for example microbeads, ${ }^{[53]}$ fingerprints ${ }^{[54]}$ or cells. ${ }^{[55]}$ The imaging of processes limited near the electrode surface can be easily visualized, avoiding refraction from a thick layer of solution that decreases image resolution. The electrochemically-induced visualization is a powerful imaging tool in particular to analyze biological samples where the autofluorescence might significantly contribute to the signal to noise ratio. ECL of luminol was presented for imaging of active membrane cholesterol at single living cells. ${ }^{[55]}$ Imaging was also performed with FTO assembled in a transparent electrochemical cell coupled with a microscope and a CCD camera. Microbeads conjugated with $\mathrm{Ru}(\mathrm{bpy}) 3_{3^{2+}}$, like in immunoassay, were imaged by $\mathrm{ECL}$ and $\mathrm{Ru}(\mathrm{bpy}) 3^{2+}$

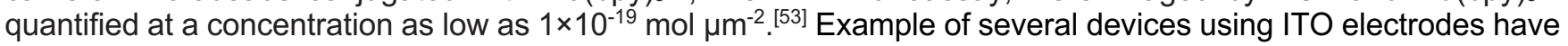
been reported, from analytics to light emitters. A portable and thermal-powered ECL sensor composed of an electrode array, where results were acquired by smart cell phone. ${ }^{[56]} \mathrm{An} E C L$ immunosensor was fabricated for the detection of carcinoma embryonic antigen. The ITO device was fabricated using a simple, low-cost, fast acid etch technique, which integrated counter, reference and working electrode in a single ITO slide. ${ }^{[57]} \mathrm{A}$ solid-state ECL device has been assembled with ITO anode and a porous Au cathode. The ECL quantum yields, from a complex of ruthenium(II), matched the efficiency of organic polymer based light-emitting devices. ${ }^{[58]}$ ITO nanotip array, fabricated by chemical etching, of optoelectrochemical submicrometer sensors was proposed for remote ECL imaging. This sensor array was studied with ECL model system Ru(bpy) $3^{2+} / \mathrm{TPrA}$, is able to perform remote ECL imaging with the advantages of ultramicroelectrode properties, and it also allows the parallel acquisition of large amounts of data. ${ }^{[59]}$

ITO electrodes modified with nanoparticles can lead to an increase of the ECL signal compared to bare electrodes, facilitating the electrochemical oxidation of coreactants. ${ }^{[60]}$ ITO/Au nanoparticles ${ }^{[61]}$ and ITO/ITO nanoparticles ${ }^{[62]}$ were found to be effective in increasing the ECL signal in Ru(bpy) $3^{2+} / \operatorname{TPrA}$ and QDs/DBAE and TPrA systems, respectively. Very interestingly, ITO electrodes were useful applied to imaging of nanomaterial that have different redox constants of electron transfer (ket) compared to ITO. Basically, as show in figure 4, nanoparticles deposited on ITO which exhibit higher ket for TPrA than ITO can be visualized by a CCD camera, because the emission of ECL signal is diffusion limited around the nanoparticle ${ }^{[63]}$ or by the nanoparticle itself (Figure 4). ${ }^{[64]}$ 


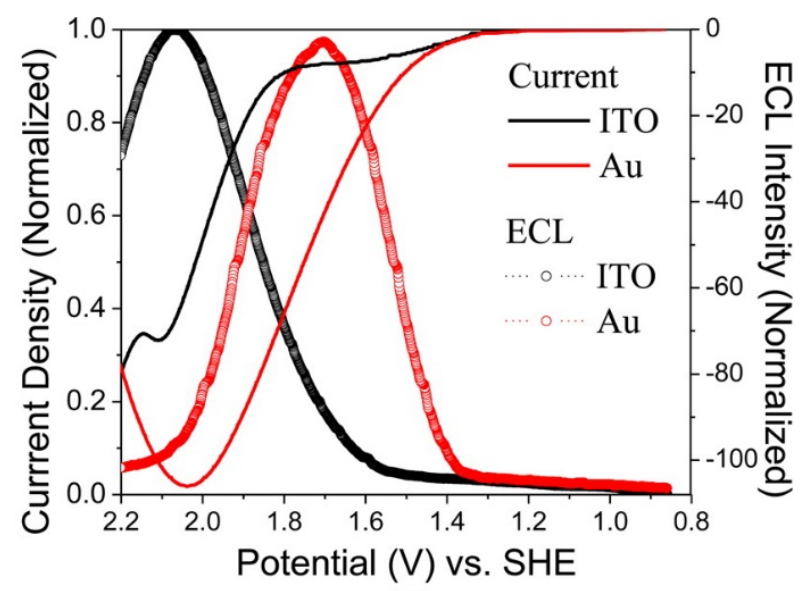

(A)

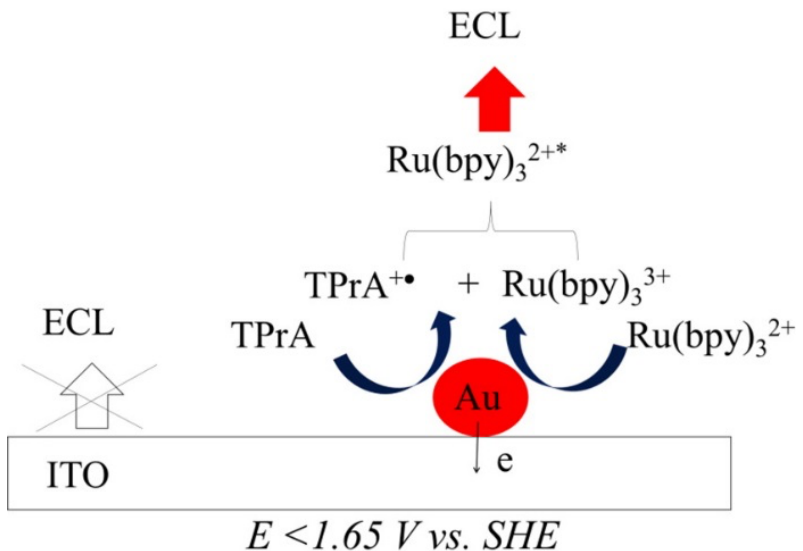

(B)

Figure 4. (A) Current density and ECL responses to electrode potential at bare ITO and Au disc electrodes in an ECL solution containing $0.1 \mathrm{M} \mathrm{TPrA}, 5 \mathrm{mM} \mathrm{Ru}(\mathrm{bpy})_{3} \mathrm{Cl}_{2}$ in $0.1 \mathrm{MPBS}$ buffer at a pH of 7.4. Potential scan rate: 100 $\mathrm{mV} / \mathrm{s}$. ECL was detected with a photomultiplier tube (PMT); (B) Au NP coated ITO for generating ECL selectively at Au NPs while minimizing background ECL from the ITO substrate by holding the electrode potential at $\leq 1.65 \mathrm{~V}$ vs SHE. Reproduced from ref. [63a], copyright 2015, with permission of American Chemical Society.

However, this sluggish kinetic on ITO, for example the oxidation of the most common TPrA coreactant, typically decreases the efficiency of the ECL generation For this reason, research on transparent electrodes moved to higher efficient materials, which retain high degree of transparency.

Carbon based materials (graphene or nanotubes) are ideal candidates for the fabrication of transparent electrodes for ECL applications, in fact they combine good conductivity, fast electron transfer and high optical transmission. However, these materials need an inert support because they are not freestanding. Commonly, graphene is transferred on glass after CVD growth on copper, or carbon nanotubes solutions were filtered onto alumina and transferred directly onto polyethylene terephthalate (PET).

Different examples of graphene modified with thin polymer films were proposed as an electrochemical platform for surface $\mathrm{ECL}$ using polymer derivate of $\mathrm{Ru}(\mathrm{bpy}) 3^{2+}{ }^{2+65]}$ Transparent single-layer graphene (SLG) generates ECL by annihilation mode of classical ECL luminophores, rubrene and 9,10-diphenylanthracene, in acetonitrile and acetonitrile/benzene and light emission measured through it. ${ }^{[4]}$ SLG displayed excellent stability, at least from ca. -2.4 to $+1.8 \mathrm{~V}$ versus SCE. Although the peak splitting between forward and reverse sweeps in voltammetry was larger in comparison to metal electrodes due to in-plane resistance, this may be decreased with samples that are defect-free or have larger grain size. The use of SLG electrodes with detection through the graphene window reduced apparent peak shifts by up to $10 \mathrm{~nm}$ in peak wavelength, due to inner filter effects.

Carbon nanotube-based electrodes are excellent materials for ECL applications thanks to the low overpotential of oxidation for amine derivatives, which are the most commonly used coreactants. This reflects in 10-fold increasing of ECL emission compared to ITO (Figure 5), for the system Ru(bpy) $3^{2+} /$ TPrA, as the ket of TPrA oxidation 
varies from $3 \times 10^{-5} \mathrm{~cm} \mathrm{~s}^{-1}$ to $0.3 \mathrm{~cm} \mathrm{~s}^{-1}$, from ITO to CNT, respectively. ${ }^{[48]}$ By using CNTs, it was possible to achieve transparency, higher than $90 \%$, with good conductivity, furthermore PET substrate offers the advantage of flexibility. CNT electrode was applied, for the first time, to the ECL imaging of microbeads, which were used to mimic a real biological sample such as visualization of single-cell.

The treatment of CNT film with a capacitive coupled plasma technique permits to obtain a patterned surface of CNTs on a non-conductive, transparent and flexible surface of PET. ${ }^{[66]}$
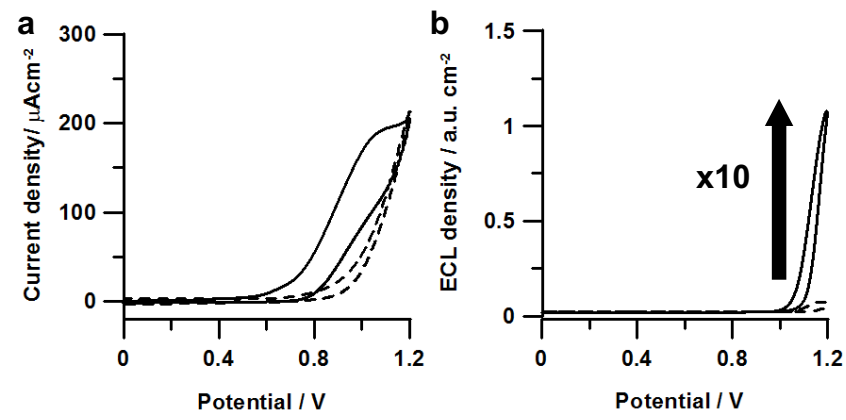

Figure 5. a) cyclic voltammogram and b) $E C L$ versus potential for $10 \mathrm{mM}\left[R u(b p y)_{3}\right]^{2+}, 80 \mathrm{~mm}$ TPrA, in phosphate buffer $0.1 \mathrm{M}$. Solid curves correspond to the CNT-based electrode, whereas dashed curves are for the ITO electrode. Scan rate $=0.1 \mathrm{Vs}^{-1}, \mathrm{PMT}=750 \mathrm{~V}$. All potentials are reported vs. $\mathrm{Ag} / \mathrm{AgCl}(3 \mathrm{M})$. Reproduced from ref. [48], copyright 2015, with permission of Wiley.

\section{Paper based materials and disposable}

Paper, as a common material used widely in our daily life, has a lot of advantages, such as low cost and availability, thickness, light weight, flexibility to treatment with the desired shapes and functionalities, easy disposal after use, i.e. not polishing procedure required. All these intrinsic properties allow the successful developments of the microfluidic paper-based analytical devices ( $\mu$-PADs) ${ }^{[67,68]}$ In particularly, these devices have been applied to design diverse ECL sensing systems ${ }^{[67]}$ Hogan and co-workers developed nicely paper-based microfluidic sensors based on ECL detection. ${ }^{[69]}$ The paper microfluidic elements were prepared using Adobe illustrator by inkjet printing the fluidic channels in filter paper, filling the detection zone with an ECL active luminophore, and fixed onto the surface of the screen-printed electrode (SPE) for ECL measurement. By analyzing the red pixel intensity in digital images of the ECL emission recorded by a cell phone, coreactant DBAE could be detected to levels of $250 \mu \mathrm{M}$; lower detection limits were reached with conventional photodetector.

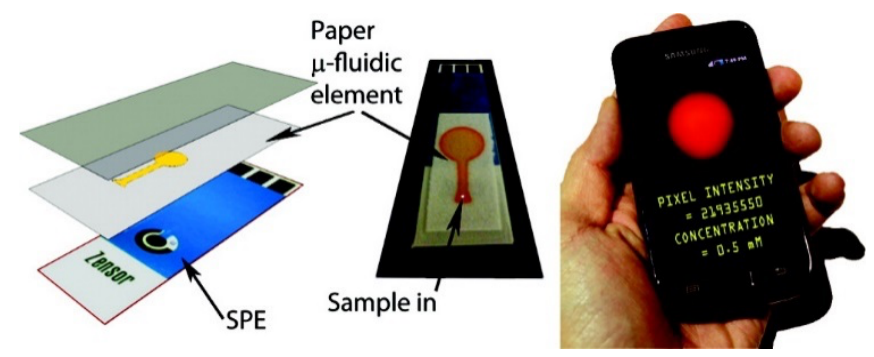

Figure 6. Fabrication and operation of a paper-based microfluidic ECL sensor. The paper microfluidics are produced in bulk using a conventional inkjet printer. ECL emission is recorded with a cell phone. Reprinted from ref. [69], copyright 2011, with permission of American Chemical Society.

Wang and co-workers demonstrated also the development of ECL microfluidic sensing platforms on filter paper by photolithography. ${ }^{\left[70,{ }^{71]}\right.}$ In their case, the paper impregnated with photo-resist was exposed to the UV lamp through a printed photo-mask, which then triggers the polymerization in only the projected area on the paper.

The unexposed resist can be washed away by aqueous or organic solvent. Finally, further treatments are used to form a self-powered printed circuit board on the paper by assembling primary battery. ECL from the luminol/ $\mathrm{H}_{2} \mathrm{O}_{2}$ and $\mathrm{Ru}(\mathrm{bpy}){ }_{3}{ }^{2+} / \mathrm{TPrA}$ systems were demonstrated respectively. Glucose sensing from $10 \mathrm{nM}$ to $10 \mu \mathrm{M}$ was reported in this platforms. Such microfluidic paper could also be prepared by other methods, including wax patterning, ${ }^{[72-76]}$ laser printing with toner ${ }^{[77]}$ For example, porous Au-paper working electrodes were developed by the growth of an interconnected Au NP layer on the surfaces of cellulose fibers to enhance the conductivity of the paper sample zone. ${ }^{[7]}$ In this way, Yu and co-workers presented a 3D microfluidic origami ECL aptamer-device for ATP for point- 
of-care diagnosis. In brief, paper-based materials are simple, affordable, rapid, and robust for ECL analysis and they can easily be combined with microfluidics. Therefore, such materials can expand the applications fields of ECL for medical applications in developing countries and remote communities.

\section{Others}

Among the extremely large diversity of electrode materials, boron-doped diamond (BDD) is considered as one of the most efficient for electrochemical studies. ${ }^{[78,79]}$ Diamond is a large band gap semiconductor and, therefore, possesses optical transparency in the visible and IR regions of the spectrum. However, a key issue is to balance the boron-doping level to impart sufficient electrical conductivity while maintaining optical transparency. ${ }^{[80]}$ Although this electrode material is widely applied in electrochemistry and results very promising in the ECL fields only few examples are reported in literature.

Thanks to the pioneering works of the Fujishima group ${ }^{[81,82]} \mathrm{ECL}$ emission was demonstrated on BDD thin films. In comparison to GCE and polycrystalline Pt, BDD exhibits superior properties, such as the fast reaction rate for the charge-transfer reaction, wide potential window, low background current, high sensitivity, and high chemical stability ${ }^{[83]}$ Therefore, complex ECL mechanisms could be verified separately at the diamond surface. Due to its electrochemical stability, BDD is more suitable for ECL study at high oxidation potential. Meanwhile, BDD microelectrode arrays have been prepared by various methods, which have extended its application in ECL measurements. ${ }^{[84,85]}$

Table 1. Decision table for electrode materials in ECL.

\begin{tabular}{|c|c|c|c|c|c|}
\hline \multirow{2}{*}{$\begin{array}{l}\text { Electrode } \\
\text { material }\end{array}$} & \multirow{2}{*}{$\begin{array}{c}\text { Annihilation } \\
E^{\prime} L^{a}\end{array}$} & \multicolumn{2}{|c|}{ Coreactant $\mathrm{ECL}^{\mathrm{b}}$} & \multirow[t]{2}{*}{ Advantages } & \multirow[t]{2}{*}{ Disadvantages } \\
\hline & & $\begin{array}{l}\text { "oxidative- } \\
\text { reduction" }\end{array}$ & $\begin{array}{l}\text { "reductive- } \\
\text { oxidation" }\end{array}$ & & \\
\hline Platinum & $(\dot{*})$ & $\ddot{\theta}$ & $\ddot{\theta}$ & $\begin{array}{l}\text { Fast electron transfer } \\
\text { in aprotic condition }\end{array}$ & $\begin{array}{l}\text { Small potential windows in } \\
\text { water } \\
\text { Generation of metal oxides } \\
\text { Expensive }\end{array}$ \\
\hline Gold & $(\dot{)})$ & $(\bullet)$ & $\ddot{\theta}$ & $\begin{array}{l}\text { Fast electron transfer } \\
\text { in aprotic condition } \\
\text { Easy to functionalize }\end{array}$ & $\begin{array}{l}\text { Small potential windows in } \\
\text { water } \\
\text { Generation of metal oxides } \\
\text { Expensive }\end{array}$ \\
\hline Carbon-based & $(\ddot{*})$ & $(\ddot{*})$ & $(\ddot{)})$ & $\begin{array}{l}\text { Low cost } \\
\text { Fast electron transfer } \\
\text { for TPrA oxidation }\end{array}$ & $\begin{array}{l}\text { High unspecific ECL signal } \\
\text { Possibility to functionalize }\end{array}$ \\
\hline Transparent & $(\bullet)$ & $(\bullet)$ & $(\bullet)$ & $\begin{array}{l}\text { Low cost } \\
\text { Acquisition of ECL } \\
\text { through electrode } \\
\text { Microscopy }\end{array}$ & $\begin{array}{l}\text { Slow electron transfer and } \\
\text { small potential windows } \\
\text { (ITO) }\end{array}$ \\
\hline Paper based & $\ddot{8}$ & $(\dot{)})$ & (ن) & $\begin{array}{l}\text { Low cost } \\
\text { Disposable } \\
\text { Portable device }\end{array}$ & $\begin{array}{l}\text { High unspecific ECL signal } \\
\text { Difficult to functionalize } \\
\text { Not stable in aprotic solvent }\end{array}$ \\
\hline
\end{tabular}


[a] Aprotic solvent, typically acetonitrile or dichloromethane. [b] Water based solvent. $\odot$ : suitable, $\odot$ : semi-suitable and $\odot:$ unsuitable.

\section{Conclusions and Outlook}

Electrochemiluminescence is a very powerful analytical technique with a spread commercialization of immunoassays and many applications in biosensing. The main drawbacks of this transduction methodology are related to the kinetic of electrochemical heterogeneous reactions and the electrode modifications that occur during the application of the electrochemical stimulus. For these reasons, the proper choice of the electrode material depends on many experimental parameters, such as the coreactant or the solvent. In many cases, it might be the limiting factor for an optimal analytical signal. Here we discussed the properties of the most common electrode materials used in ECL applications and some strategies to minimize their modification, such as surfactants, alkanthiols or halides. Although the right selection of the electrode material might increase the ECL intensity of few orders of magnitude, all the material reported here show some advantages and disadvantages also depending on the strategy selected for the excited state generation. We resume all the materials reported herein in a practical decision table (Table 1) that summarizes the best matching between electrode material and experimental conditions. However, we strongly recommend a deep understanding of the whole ECL system and the target application to select the most suitable electrode material.

\section{Acknowledgements}

HL acknowledges the China Scholarship Council for his PhD fellowship.

Keywords: Electrochemiluminescence • Electrochemistry • Electrode materials • Biosensors • Coreactant mechanism

[1] Electrogenerated Chemiluminescence, (Eds.: A.J. Bard), Marcel Dekker, Inc. New York, 2004

[2] M. M. Richter, Chem. Rev. 2004, 104, 3003-3036.

[3] a) C. Amatore, B. Fosset, K. M. Maness, R. M. Wightman, Anal. Chem. 1993, 65, 2311-2316. b) C. Amatore, C. Pebay, L. Servant, N. Sojic, S. Szunerits, L. Thouin, ChemPhysChem 2006, 7, 1322-1327. c) S. Szunerits, J. M. Tam, L. Thouin, C. Amatore, D. R. Walt, Anal. Chem. 2003, 75, 4382-4388. d) O. V. Klymenko, I. Svir, A. Oleinick, C. Amatore, ChemPhysChem 2012, 13, 845-859.

[4] M. Hesari, Z. Ding, J. Electrochem. Soc. 2016, 163, H3116-H3131.

[5] a) W. Miao, Chem. Rev. 2008, 108, 2506-2553; b) E. Rampazzo, S. Bonacchi, D. Genovese, R. Juris, M. Marcaccio, M. Montalti, F. Paolucci, M. Sgarzi, G. Valenti, N. Zaccheroni, L. Prodi, Coord. Chem. Rev. 2012, 256, 1664-1681.

[6] R. J. Forster, P. Bertoncello, T. E. Keyes, Annu. Rev. Anal. Chem. 2009, 2, 359-385.

[7] a) L. Hu, G. Xu, Chem. Soc. Rev. 2010, 39, 3275-3304; b) Z. Liu, W. Qi, G. Xu, Chem. Soc. Rev. 2015, 44, 3117-3142.

[8] according to ISI Web of Knowledge (January 2016)

[9] a) H. Habtamu, M. Sentic, M. Silvestrini, L. De Leo, T. Not, S. Arbault, D. Manojlovic, N. Sojic, P. Ugo Anal. Chem., 2015, 87, 12080-12087; b) Q. Dang, H. Gao, Z. Li, H. Qi, Q. Gao, C. Zhang, Anal. Bioanal. Chem. 2016, DOI 10.1007/s00216-016-9360-z; c) G. Valenti, E. Rampazzo, E. Biavardi, E. Villani, G. Fracasso, M. Marcaccio, F. Bertani, D. Ramarli, E. Dalcanale, F. Paolucci, L. Prodi, Faraday Discuss. 2015, 185, 299-309

[10] Roche Diagnostics Corp., www.roche.com (08 August 2016).

[11] Meso Scale Discovery, www.mesoscale.com (08 August 2016).

[12] a) Dropsens. http://www.dropsens.com (08 August 2016); b) M. M. P. S. Neves, P. Bobes-Limenes, A. Pérez-Junquera, M. B. González-García, D. Hernández-Santos, P. Fanjul-Bolado Anal. Bioanal. Chem. 2016, DOI 10.1007/s00216-016-9669-7.

[13] W. Miao, J. P. Choi, A. J. Bard, J. Am. Chem. Soc. 2002, 124, 14478-14485.

This item was downloaded from IRIS Università di Bologna (https://cris.unibo.it/)

When citing, please refer to the published version. 
[14] a) M. Sentic, M. Milutinovic, F. Kanoufi, D. Manojlovic, S. Arbault, N. Sojic, Chem. Sci. 2014, 5, 2568-2572; b) K. Imai, G. Valenti, E. Villani, S. Rapino, E. Rampazzo, M. Marcaccio, L. Prodi, F. Paolucci J. Phys. Chem. C 2015, 119, 26111-26118.

[15] a) I. Svir, A. Oleinick, O. V. Klymenko, C. Amatore, ChemElectroChem 2015, 2, 811-818; b) O. V. Klymenko, I. Svir, C. Amatore, ChemPhysChem 2013, 14, 2237-2250.

[16] a) A. Adenier, M. M. Chehimi, I. Gallardo, J. Pinson, N. Vilà Langmuir. 2004, 20, 8243-8253; b) M. Aufray, A. A. Roche Appl. Surf. Sci. 2008, 254, 1936-1941.

[17] a) C. K. Mann, Anal. Chem. 1964, 36, 2424-2426; b) S. D. Ross, Tetrahedron Lett. 1973, 15, 1237-1240; c) N. E. Tokel, A. J. Bard, J. Am. Chem. Soc. 1972, 94, 2862-2863; I. Rubinstein, A. J. Bard, J. Am. Chem. Soc. 1981, 103, 512-516; e) H. S. White, A. J. Bard, J. Am. Chem. Soc. 1982, 104, 6891-6895; f) A. Kapturkiewicz, J. Nowacki, P. Borowicz, Electrochim. Acta 2005, 50, 3395-3400.

[18] a) A. Kapturkiewicz, Anal. Bioanal. Chem. 2016, DOI 10.1007/s00216-016-9615-8, b) W. Sun, S. Sun, N. Jiang, H. Wang, X. Peng, Organometallics, 2015, 34, 3385-3389; c) M. Bandini, M. Bianchi, G. Valenti, F. Piccinelli, F. Paolucci, M. Monari, A. Umani-Ronchi, M. Marcaccio, Inorg. Chem. 2010, 49, 1439-1448; d) J. M. Fernandez-Hernandez, E. Longhi, R. Cysewski, F. Polo, H. P. Josel, L. De Cola, Anal. Chem. 2016, 88, 4174-4178; e) Y. Zhou, H. Gao, X. Wang, H. Qi, Inorg. Chem. 2015, 54, 1446-1453.

[19] L. Della Ciana, S. Zanarini, R. Perciaccante, E. Marzocchi, G. Valenti, J. Phys. Chem. C 2010, 114, 36533658.

[20] A. B. Nepomnyashchii, A. J. Pistner, A. J. Bard, J. Rosenthal, J. Phys. Chem. C 2013, 117, 5599-5609.

[21] a) F. Polo, F. Rizzo, M. Veiga-Gutierrez, L. De Cola, S. Quici, J. Am. Chem. Soc. 2012, 134, 15402-15409; b) G. Valenti, C. Bruno, S. Rapino, A. Fiorani, E. A. Jackson, L. T. Scott, F. Paolucci, M. Marcaccio, J. Phys. Chem C 2010, 114, 19467-19472; c) G. Valenti, A. Fiorani, S. Di Motta, G. Bergamini, M. Gingras, P. Ceroni, F. Negri, F. Paolucci, M. Marcaccio, Chem. Eur. J. 2015, 21, 2936-2947.

[22] Y. Zu, A. J. Bard, Anal. Chem. 2000, 72, 3223-3232

[23] S. A. Kitte, C. Wang, S. Li, Y. Zholudov, L. Qi, J. Li, G. Xu, Anal. Bioanal. Chem. 2016, DOI:10.1007/s00216-016-9409-z.

[24] G. Xu, H. L. Pang, B. Xu, S. Dong, K. Y Wong, Analyst, 2005, 130, 541-544.

[25] a) S. Workman, M. M. Richter, Anal. Chem. 2000, 72, 5556-5561; b) B. Factor, B. Muegge, S. Workman, E. Bolton, J. Bos, M. M. Richter, Anal. Chem. 2001, 73, 4621-4624.

[26] M. Hesari, Z. Ding, J. Electrochem. Soc. 2016, 163, H3116-H3131.

[27] K. Muzyka, Biosens. Bioelectron. 2014, 54, 393-407;

[28] a) H. Angerstein-Kozlowska, B. E. Conway, A. Hamelin, L. Stoicoviciu, J. Electroanal. Chem. 1987, 228, 429-453; b) B. E. Conway, B. Barnett, H. Angerstein-Kozlowska, J. Chem. Phys. 1990, 93, 8361-8373.

[29] S. Nishida, Y. Harima, K. Yamashita, Inorg. Chem. 1989, 28, 4073-4077.

[30] Y. Zu, A. J. Bard, Anal. Chem. 2001, 73, 3960-3964 a)F. Li, Y. Zu, Anal. Chem. 2004, 76, 1768-1772; b) Y. Zu, F. Li, Anal. Chim. Acta 2005, 550, 47-52

[31] a) H. Cui, Z. F. Zhang, G. Z. Zou, X. Q. Lin, J. Electroanal. Chem. 2004, 566, 305-313; b) H. X. Yu, H. Cui, J. Electroanal. Chem. 2005, 580, 1-8.

[32] Y. P. Dong, H. Cui, C. M. Wang, J. Phys. Chem. B 2006, 110, 18408-18414.

[33] Y. Xia, X. Deng, S. Yan, C. Gao, C. Ma, L. Jin, Dalton Trans. 2015, 44, 11929-11934;

[34] X. Li, R. Wan, X. Zhang, Microchim. Acta 2011, 172, 285-290.

[35] W. Gao, X. H. Xia, J. J. Xu, H. Y. Chen, J. Phys. Chem. C 2007, 111, 12213-12219

[36] J. K. Leland, M. J. Powell, J. Electrochem. Soc. 1990, 137, 3127-3131.

[37] Z. Chen, Y. Zu, J. Phys. Chem. C 2008, 112, 16663-16667.

[38] a) E. Kerr, E. H. Doeven, G. J. Barbante, C. F. Hogan, D. J. Bower, P. S. Donnelly, T. U. Connell, P. S. Francis, Chem. Sci. 2015, 6, 472-479; b) M. A. Haghighatbin, S. C. Lo, P. L. Burn, C. F. Hogan, Chem. Sci. 2016, DOI: 10.1039/c6sc01912a.

[39] G. J. Barbante, N. Kebede, C. M. Hindson, E. H. Doeven, E. M. Zammit, G. R. Hanson, C. F. Hogan, P. S. Francis, Chem. Eur. J. 2014, 20, 14026-14031.

[40] A. J. Stewart, J. Hendry, L. Dennany Anal. Chem. 2015, 87, 11847-11853.

[41] V. Zamolo, G. Valenti, E. Venturelli, O. Chaloin, M. Marcaccio, S. Boscolo, V. Castagnola, S. Sosa, F. Berti, G. Fontanive, M. Poli, A. Tubaro, A. Bianco, F. Paolucci, M. Prato, ACS Nano 2012, 6, 79897997.

[42] B. Wu, C. Miao, L. Yu, Z. Wang, C. Huang, N. Jia, Sens. Actuator B-Chem. 2014, 195, $22-27$.

[43] a) A. Venkatanarayanan, K. Crowley, E. Lestini, T. E. Keyes, J. F. Rusling, R. J. Forster, Biosens. Bioelectron. 2012, 31, 233-239; b) N. P. Sardesai, J. C. Barron, J. F. Rusling, Anal. Chem. 2011, 83, 6698-6703.

[44] a) F. Li, Y. Yu, Q. Li, M. Zhou, H. Cui Anal. Chem., 2014, 86, pp 1608-1613; b) Y. Sua, Y. Lv, RSC Adv. 2014, 4, 29324-29339. c) S. Deng, J. Lei, Y. Huang, Y. Cheng, H. Ju, Anal. Chem. 2013, 85, 5390-5396.

[45] Z. Guo, Y. Sha, Y. Hu, S. Wang Chem. Commun., 2016, 52, 4621-4624

[46] T. C. Cristarella, A. J. Chinderle, J. Hui, J. Rodríguez-López, Langmuir 2015, 31, 3999-4007

[47] G. Valenti, M. Zangheri, S. E. Sansaloni, M. Mirasoli, A. Penicaud, A. Roda, F. Paolucci, Chem. Eur. J. 2015, 21, 12640-12645

[48] K. L. Chopra, S. Major, D. K. Pandya, Thin Solid Films 1983, 102, 1-46.

This item was downloaded from IRIS Università di Bologna (https://cris.unibo.it/)

When citing, please refer to the published version. 
[49] J. D. Benck, B. A. Pinaud, Y. Gorlin, T. F. Jaramillo, PLoS ONE 2014, 9, e107942.

[50] a) L. Petrizza, D. Genovese, G. Valenti, M. lurlo, A. Fiorani, F. Paolucci, S. Rapino, M. Marcaccio, Electroanal. 2016, 28, DOI: 10.1002/elan.201600262; b) K. Hou, D. Puzzo, M. G. Helander, S. S. Lo, L. D. Bonifacio, W. Wang, Z. H. Lu, G. D. Scholes, G. A. Ozin, Adv. Mater. 2009, 2, 2492-2496; c) R. Huang, M. Y. Wei, L. H. Guo, J. Electroanal. Chem. 2011, 656, 136-139.

[51] R. Wilson, H. Akhavan-Tafti, R DeSilva, A. P. Schaap, Electroanal. 2001, 13, 1083-1092.

[52] L. S. Dolci, S. Zanarini, L. Della Ciana, F. Paolucci, A. Roda, Anal. Chem. 2009, 81, 6234-6241

[53] a) L. Xu, Y. Li, S. Wu, X. Liu, B. Su, Angew. Chem. Int. Ed. 2012, 51, 8068-8072; b) Y. Li, L. Xu, Y. He, B. Su, Electrochem. Commun. 2013, 33, 92-95.

[54] J. Zhou, G. Ma, Y. Chen, D. Fang, D. Jiang, H. Y. Chen, Anal.Chem. 2015, 87, 8138-8143.

[55] N. Hao, M. Xiong, J. D. Zhang, J. J. Xu, H. Y. Chen, Anal. Chem. 2013, 85, 11715-11719.

[56] S. Wang, Y. Zhang, J. Yu, X. Song, S. Ge, M. Yan, Sens. Actuator B-Chem. 2012, 171-172, 891-898.

[57] C. M. Elliott, F. Pichot, C. J. Bloom, L. S. Rider, J. Am. Chem. Soc. 1998, 120, 6781-6784.

[58] A. Chovin, P. Garrigue, P. Vinatier, N. Sojic, Anal. Chem. 2004, 76, 357-364.

[59] F. R. F. Fan, A. J. Bard, Nano Lett. 2008, 8, 1746-1749.

[60] S. Wang, E. Harris, J. Shi, A. Chen, S. Parajuli, X. Jing, W. Miao, Phys. Chem. Chem. Phys. 2010, 12, 10073-10080.

[61] R. Huang, M. Y. Wei, L. H. Guo, J. Electroanal. Chem. 2011, 656, 136-139.

[62] a) S. Pan, J. Liu, C. M. Hill, J. Phys. Chem. C 2015, 119, 27095-27103; b) A. J. Wilson, K. Marchuk, K. A. Willets, Nano Lett. 2015, 15, 6110-6115.

[63] Y. L. Chang, R. E. Palacios, F. R. F. Fan, A. J. Bard, P. F. Barbara, J. Am. Chem. Soc. 2008, 130, 8906-8907.

[64] N. L. Ritzert, W. Li, C. Tan, G. G. Rodríguez-Calero, J. Rodríguez-López, K. Hernández-Burgos, S. Conte, J. J. Parks, D. C. Ralph, H. D. Abruña, Faraday Discuss. 2014, 172, 27-45.

[65] K. N. Han, C. A. Li, M. P. N. Bui, G. H. Seong, Langmuir 2010, 26, 598-602.

[66] L. Ge, J. Yu, S. Ge, M. Yan, Anal. Bioanal. Chem. 2014, 406, 5613-5630.

[67] D. M. Cate, J. A. Adkins, J. Mettakoonpitak, C. S. Henry Anal. Chem. 2015, 87, 19-41.

[68] J. L. Delaney, C. F. Hogan, J. Tian, W. Shen, Anal. Chem. 2011, 83, 1300-1306.

[69] X. Zhang, J. Li, C. Chen, B. Lou, L. Zhang, E. Wang, Chem. Commun. 2013, 49, 3866-3868.

[70] W. Gu, Y. Xu, B. Lou, Z. Lyu, E. Wang, Electrochem. Commun. 2014, 38, 57-60.

[71] M. Zhang, L. Ge, S. Ge, M. Yan, J. Yu, J. Huang, S. Liu, Biosens. Bioelectron. 2013, 41, 544-550.

[72] W. Li, L. Li, S. Ge, X. Song, L. Ge, M. Yan, J. Yu, Chem. Commun. 2013, 49, 7687-7689.

[73] S. Wang, W. Dai, L. Ge, M. Yan, J. Yu, X. Song, S. Ge, J. Huang, Chem. Commun. 2012, 48, 99719973.

[74] J. Yan, L. Ge, X. Song, M. Yan, S. Ge, J. Yu, Chem. Eur. J. 2012, 18, 4938-4945.

[75] J. Yan, M. Yan, L. Ge, J. Yu, S. Ge, J. Huang, Chem. Commun. 2013, 49, 1383-1385.

[76] C. G. Shi, X. Shan, Z. Q. Pan, J. J. Xu, C. Lu, N. Bao, H. Y. Gu, Anal. Chem. 2012, 84, 3033-3038.

[77] R. L. McCreery, Chem. Rev. 2008, 108, 2646-2687.

[78] Diamond Electrochemisty, (Eds.: A. Fujishima, Y. Einaga, T. N. Rao, D. A. Tryk), BKC Inc., Tokyo and Elsevier, Amsterdam, 2005

[79] J. Stotter, Y. Show, S. Wang, G. Swain, Chem. Mater. 2005, 17, 4880-4888.

[80] K. Honda, M. Yoshimura, Tata N. Rao, A. Fujishima J. Phys. Chem. B 2003, 107, 1653-1663.

[81] K. Honda, Y. Yamaguchi, Y. Yamanaka, M. Yoshimatsu, Y. Fukuda, A. Fujishima, Electrochim. Acta 2005, 51, 588-597.

[82] K. Honda, T. Noda, M. Yoshimura, K. Nakagawa, A. Fujishima, J. Phys. Chem. B 2004, 108, 1611716127.

[83] Y. Yang, J. W. Oh, Y. R. Kim, C. Terashima, A. Fujishima, J. S. Kim, H. Kim Chem. Commun. 2010, 46, 5793-5795.

[84] M. Sentic, F. Virgilio, A. Zanut, D. Manojlovic, S. Arbault, M. Tormen, N. Sojic, P. Ugo, Anal. Bioanal. Chem. 2016, DOl:10.1007/s00216-016-9504-1. 